Recibido: 05/10/2021 --- Aceptado: 02/11/2021 --- Publicado: 10/12/2021

\title{
CAMBIOS EN LA PROGRAMACIÓN TELEVISIVA EN ANDALUCÍA DEBIDO A LA PANDEMIA POR LA COVID-19. EL CASO DEL CARNAVAL DE CÁDIZ
}

\section{CHANGES IN TELEVISION PROGRAMMING IN ANDALUSIA DUE TO THE COVID-19 PANDEMIC. THE CASE OF CÁDIZ CARNIVAL}

\author{
(D) Estrella Fernández Jiménez ${ }^{\mathbf{1}}$ : Universidad de Sevilla. España \\ estrellaffjj@us.es
}

\section{Cómo citar el artículo:}

Fernández Jiménez, E. (2021). Cambios en la programación televisiva en Andalucía debido a la pandemia por la COVID-19. El caso del Carnaval de Cádiz. Revista de Comunicación de la SEECI, 54, 83-102. http://doi.org/10.15198/seeci.2021.54.e741

\section{RESUMEN}

Los medios de comunicación han sido el sector que no solo no ha parado su actividad, sino que la ha incrementado debido a la alta demanda de información por parte de la población para informarse y también para entretenerse. Nuestro objetivo principal es abordar cómo los medios de comunicación, en especial la televisión, se han adaptado a la nueva situación. En concreto la programación referida a la retransmisión del Carnaval de Cádiz. En 2021 las cadenas de televisión han tenido que generar ese contenido para cubrir la programación especial de esas fechas. En este trabajo mostramos una panorámica general analizando las parrillas de programación así como los contenidos generados por las televisiones. Mediante la observación participante, entrevistas en profundidad a agentes implicados en la dirección y desarrollo de los programas estudiados y análisis de las parrillas televisivas, observamos que, en esta ocasión, la creatividad ha surgido de los guionistas o directores de programas y no del producto cultural que es el Carnaval de Cádiz, como históricamente ha ocurrido. Sabemos que el contenido aquí estudiado puede quedar desfasado con rapidez debido a sus propias características, pero al ser un hecho excepcional debe ser estudiado como momento histórico que se suma a los diversos cambios y adaptaciones que la sociedad ha tenido que hacer debido a la pandemia.

\footnotetext{
${ }^{1}$ Estrella Fernández Jiménez: Licenciada en Comunicación audiovisual y doctora en Comunicación (Universidad de Sevilla), ha trabajado como profesora en el departamento de marketing y Comunicación de la Universidad de Cádiz. Actualmente pertenece al Equipo de Investigación de la Imagen y la Cultura Visual en el ámbito de la comunicación Audiovisual (US).

estrellaffjj@us.es
} 
Fernández Jiménez, E. Cambios en la programación televisiva en Andalucía debido a la pandemia por la COVID-19. El caso del Carnaval de Cádiz

PALABRAS CLAVE: Programación - televisión - carnaval - COVID-19 - Cádiz Creatividad - Andalucía

\begin{abstract}
Media has been the business area that not only has not stopped its activity, but also has increased it due to the high demand of information by the population to inform and entertain themselves. Our main goals to address how the media, especially television, have adapted to the new situation. Specifically, the programming referring to the retransmission of the Cádiz Carnival. In 2021, television networks have had to created that content to cover the special programming of those dates. In this work we show a general overview analyzing the broadcast programming as well as the content created by networks. Through participating observation, in-depth interviews with agents involved in the making and development of the programs studied and analysis of television programming, we note that, in this occasion, creativity has emerged from the scriptwriters or program directors and not from the cultural product itself that is the Cádiz Carnival, as it has historically happened. We know that the content studied here can quickly become out of step due to its own characteristics, but since it is an exceptional event, it must be studied as a historical moment that adds to the various changes and adaptations that society has had to make because of the pandemic.
\end{abstract}

KEY WORDS: Programming - television - carnival - COVID-19 - Cádiz - Creativity Andalusia

\title{
ALTERAÇÕES NA PROGRAMAÇÃO TELEVISIVA NA ANDALUZIA POR CAUSA DA PANDEMIA DE COVID-19. O CASO DO CARNAVAL CÁDIZ
}

\section{RESUMO}

Os meios de comunicação têm sido o setor que não somente não parou a sua atividade, como a aumentou devido à grande procura de informação por parte da população para se informar e também para se divertir. Nosso principal objetivo é abordar como os meios de comunicação, especialmente a televisão, se adaptaram à nova situação. Especificamente, a programação referente à transmissão do Carnaval de Cádiz. Em 2021, as redes de televisão tiveram que gerar esse conteúdo para cobrir a programação especial dessas datas. Neste trabalho, apresentamos uma visão geral analisando as grades de programação e também o conteúdo gerado pelos canais de televisão. Por meio de observação participante, entrevistas em profundidade com agentes envolvidos na direção e desenvolvimento dos programas estudados e análise das grades televisivas, observamos que, nesta ocasião, a criatividade emergiu dos roteiristas ou diretores de programas e não do produto cultural que é o Carnaval de Cádiz, como tem acontecido historicamente. Sabemos que o conteúdo aqui estudado pode rapidamente desatualizar-se pelas suas próprias 
Fernández Jiménez, E. Cambios en la programación televisiva en Andalucía debido a la pandemia por la COVID-19. El caso del Carnaval de Cádiz

características, mas por se tratar de um acontecimento excepcional, deve ser estudado como um momento histórico que se soma às várias mudanças $\mathrm{e}$ adaptações que a sociedade teve que realizar devido a pandemia.

PALAVRAS CHAVE: Programação - televisão - carnaval - COVID-19 - Cádiz Criatividade - Andaluzia

\section{INTRODUCCIÓN}

El Carnaval de Cádiz fue una de las últimas fiestas multitudinarias que pudieron celebrarse en España en 2020, ya que días más tarde de su conclusión se decretó el estado de alarma nacional debido a la pandemia generada por el virus Covid-19.

El desarrollo del Carnaval de Cádiz viene determinado por dos momentos clave. Por un lado acontece el COAC (Concurso Oficial de Agrupaciones Carnavalescas) que se celebra en El Gran Teatro Falla de Cádiz. Y por otro lado, encontramos el Carnaval en la calle que comienza tras el concurso y después del pregón de dicha fiesta. El concurso en 2020 tuvo lugar entre los días 20 de enero (en la categoría de adultos) y 21 de febrero, día de la final del concurso. El Carnaval en la calle, o Carnaval Oficial, se desarrolló del 22 de febrero al 1 de marzo. A estas fechas hay que añadirles el llamado «Carnaval chiquito» o «Carnaval de los jartibles», que aconteció el fin de semana comprendido entre el 6 y 8 de marzo de 2020. El estado de alarma en España se decretó una semana más tarde. Con lo cual, fue de los últimos acontecimientos multitudinarios que pudieron celebrarse con normalidad previos a la pandemia.

La coincidencia de fechas ha hecho que el carnaval pudiera celebrarse en 2020, al contrario que las festividades propias de la primavera en la región andaluza que fueron suspendidas en ese año, como son la Semana Santa, las diferentes ferias, las Cruces de Mayo, etc. O fuera de Andalucía, mencionar San Fermín cuya celebración también tuvo que ser suspendida. La suspensión de estas fiestas, para cumplir con las medidas sanitarias, dejó sin contenido a los medios de comunicación encargados de las diversas retransmisiones y reportajes. Luego no pudieron cubrir los diversos eventos derivados de dichas celebraciones. La medida tomada por la mayoría de los medios fue la reposición de las retransmisiones del año anterior, es decir, de 2019. Un ejemplo fue la Semana Santa de Málaga en Canal Sur, en la que el día de la procesión del Cristo de la Buena Muerte, se emitieron imágenes del 2019, pero con una locución hecha en directo sin que el locutor estuviera en el lugar de los hechos, se hizo mediante el teletrabajo.

Esta investigación muestra los cambios que han debido hacer las dos televisiones encargadas de la retransmisión del COAC. Dicha competición se trata de un concurso televisado y no televisivo (Fernández Jiménez, 2018), así que, por primera vez en la historia, la materia prima del Concurso, las coplas y las agrupaciones, no existen, con lo cual, los medios ya no solo se enfrentan a diseñar y gestionar el continente de ese 
producto cultural, sino que se han visto obligados a gestionar el contenido. Un contenido que antes de la pandemia llegaba a ocupar hasta seis horas de retransmisiones diarias. La prensa lleva haciéndose eco de lo que ocurre durante el Carnaval de Cádiz más de 250 años (Osuna, 2009) y la televisión tiene presencia en el Concurso desde hace más de 30. Sobre este medio, la televisión, es donde nos centramos en el presente trabajo. Estudiamos este hecho ya que es uno de los emblemas de las televisiones tanto regional de Andalucía como local de Cádiz. Ha generado, genera y seguirá generando afición y ha sido un ejercicio de adaptación televisiva (guion y producción) a las circunstancias acaecidas. Consideramos que tiene que ser destacable estos hechos ya que se ha conseguido elaborar un proceso televisivo cuando no había materia prima del producto cultural. Esto no ocurría desde que la dictadura franquista en España terminó. La elaboración de contenido carnavalesco lo consideramos ejemplo representativo de las necesidades de adaptación en los procesos de producción televisiva que lograron mantener el interés en la audiencia pese a todas las dificultades del momento.

Tradición e innovación han de ir de la mano para que elementos de la cultura popular no desaparezcan (Aragón, 2010 y Fernández Jiménez, 2018), pero ¿qué ocurre cuando es la tradición la que cambia drásticamente o desaparece, al menos momentáneamente, tal y como se conocía?

\section{OBJETIVOS}

Con este estudio pretendemos:

Dilucidar la capacidad de adaptación de la parrilla televisiva en tradiciones culturales con amplio recorrido histórico.

Estudiar cómo se generan nuevos contenidos periodísticos y televisivos cuando la materia prima principal sobre la que versan los programas cambia radicalmente.

Averiguar con qué dificultades se han encontrado los periodistas y trabajadores de los diversos medios de comunicación encargados de la retransmisión de este evento cultural.

Observar si redundan estrategias así como repetición de programas o creación de nuevos.

La metodología idónea para este estudio es la cualitativa teniendo que utilizar puntualmente la cuantitativa para extraer conclusiones en el crecimiento o descenso de producción televisiva y periodística. Y como el propio nombre de la investigación indica, se trata de un estudio de caso. Sabemos que «la posibilidad de generalización es modesta, limitada y circunstanciada» (Giménez, 2012, p. 41), pero idónea para nuestra investigación. Para un conocimiento más profundo sobre la gestión de la programación y la elaboración de los programas y las parrillas hemos realizado un cuestionario a responsables directos de estas labores. Dichos encuestados han participado en la creación de los programas que han sustituido a la programación 
tradicional de la que también han formado parte. Las personas entrevistadas han sido los periodistas Mirian Peralta, conductora del programa «El Palco del Falla» de Onda Cádiz y Manolo Casal, conductor y director del programa «El Concurso del Milenio» de Canal Sur. Sus respuestas se irán mostrando a lo largo del estudio y serán referenciadas como (Cuestionario a Peralta, 2021) y (Cuestionario a Casal, 2021). Asimismo, hemos contactado con los jefes de realización de ambas cadenas de televisión, Ángel Sanz y Juan Valentín, para que nos pudieran proporcionar las parrillas de televisión de las semanas estudiadas en este trabajo, para hacer una lectura más esclarecedora de los cambios. Puede verse un ejemplo en los Anexos. El tiempo estudiado es el comprendido entre el 10 y 23 de febrero de 2020 y entre el 1 y 14 de febrero de 2021. En estas semanas se desarrollaron las fases de cuartos de final (primera semana de la muestra), semifinales y final del concurso (segunda semana de la muestra). Se trata de una metodología múltiple necesaria para alcanzar el objetivo de visión general de los hechos y cambios acontecidos.

\section{CARNAVAL, TELEVISIÓN Y COVID-19}

Como señalábamos en la Introducción, el carnaval es un acontecimiento cíclico que transcurre habitualmente en el mes de febrero de cada año. Los carnavales de los diferentes países comparten estas fechas ya que vienen determinados por el calendario cristiano. Una vez fijado cuándo es el Domingo de Resurrección se van restando días hasta llegar a la Cuaresma y así, los tres días que anteceden al Miércoles de Ceniza, son los días de carnaval (Ramos, 2002).

Los carnavales no serían lo que son si no hubieran sido bautizados por la Iglesia; así se entiende que hayan florecido más en los países de tradición católica (Brasil, Nueva Orleans, Italia, España). En las sociedades tradicionales cumplía la función de romper la monotonía que caracterizaba sus tipos de vida, el comer beber o vestir: los bailes de máscaras contribuían a esa ruptura (Checa, 1992, p. 65).

Actualmente en Cádiz esos tres días previos al Miércoles de Ceniza se multiplican llegando a ser diez días de Carnaval Oficial. A estos diez días hay que sumarles el mes que suele durar el concurso. En general, todos los carnavales, independientemente del país donde se celebren, como ya señalaba Bajtin (1990), contienen los siguientes elementos: Inversión, Poder, libertades y libertinaje; Fiesta y Cultura Popular; Teatralidad; Vocabulario; Disfraz y Máscara; Risa; Gastronomía y Banquete; y Música.

Por otro lado:

Esta suspensión de la vida social ordinaria en gracia a un tiempo sagrado de juego, la podemos encontrar también en culturas más avanzadas. Esta significación alcanza todo lo que, de cerca o de lejos, tiene algo que ver con las saturnales y los carnavales. [...] se nos presenta el juego en primera instancia: como un intermezzo en la vida cotidiana, como ocupación en tiempo de recreo y para recreo (Huizinga, 1987, p. 26 y 27). 
El Carnaval de Cádiz contiene todo esto y además, un elemento de creatividad fundamental: las coplas. Estas coplas son la unión de la letra y la música que decenas de autores crean de manera exclusiva para el COAC (y otros tantos autores para el carnaval callejero). Estas coplas en competición en el Gran Teatro Falla de Cádiz se hicieron muy atractivas para los medios de comunicación. Al principio fue la prensa, luego la radio y posteriormente la televisión. La aparición de este último medio hizo que «A partir de ese momento, la fama a nivel local se hace regional, para toda Andalucía» (Fernández Jiménez, 2020a). La televisión ha sido y es la vía por donde el Carnaval de Cádiz (COAC) ha conseguido más fama. Ahora internet multiplica su difusión, pero con los contenidos televisivos.

Para la mayoría de la gente, la televisión es solo otro medio más de esparcimiento: es parte de nuestra vida diaria, como son los periódicos, la radio, las películas. Es una diversión que cogemos con agrado. $\mathrm{Y}$, sin embargo, la televisión está formando los gustos, las opiniones y las aspiraciones del mundo. [...] Lo que para el espectador parece ser un proceso sencillo y directo es en realidad el resultado de unas técnicas cuidadosamente seleccionadas (Millerson, 1990, p. 19).

En múltiples ocasiones, esta «selección» se ha equiparado a manipulación, pero la única selección que se produce en las televisiones que retransmiten el COAC es la que se realiza en la elaboración de resúmenes, ya que la retransmisión del concurso se hace de manera íntegra y en directo. De hecho, se trata de un acontecimiento que acapara las franjas de máxima audiencia cuyo contenido no conoce la televisión ya que los repertorios de las letras que van a interpretar los grupos son secretas. El medio de comunicación se arriesga a que las coplas que emitan en directo y en prime time vayan incluso en su contra, como ha ocurrido en varias ocasiones (Fernández Jiménez, 2020b). Por este motivo subrayamos la idea de que los medios de comunicación respecto al concurso han sido continentes de este fenómeno cultural y no han generado los contenidos.

Sobre las televisiones autonómicas «Su éxito, en la mayoría de los casos, se basa en una combinación de calidad y cercanía. Informativos y deportes son los ejes de su programación» (Ramonell, 2006, p. 35). Nosotros añadimos la programación cultural. En la televisión regional y local se cometen menos errores cuando se habla de las fiestas locales, a diferencia de las televisiones nacionales en las que por ejemplo, suele confundirse un coro con una chirigota (Fernández Jiménez, 2018). Además, las televisiones autonómicas «tienen que convivir con la contradicción de tener que compaginar una programación de servicio público, deficitaria, con otra de entretenimiento y de marcado carácter comercial, para poder recaudar algunos ingresos con la publicidad» (Ramonell, 2006, p. 37). Actualmente,

Canal Sur TV se encuentra en horas bajas en relación con la audiencia que ha tenido en otros momentos que ha superado con creces el $20 \%$. [...] en realidad han bajado todas las televisiones autonómicas «históricas» que fueron naciendo en los años 80 (Reig, Mancinas y Nogales, 2014, p. 608).

Se achaca también a la televisión regional el abuso de tópicos en su programación: 
Un ejemplo del peso de los tópicos andaluces en Canal Sur (y su éxito popular, a tenor de las audiencias) es el concurso «Se llama copla», que en 2008 hizo historia cuando la gala final del programa ocupó la franja más vista hasta el momento en la trayectoria de la televisión pública andaluza [...] en la final de 2011, el programa volvió a ser líder de audiencia, logrando récord de temporada. (Pellisser Rossell y Pineda, 2014, p. 825).

La televisión ha de innovar en su parrilla para conseguir nueva audiencia, pero lo cierto es que también es cauta, ya que siempre se va a preferir ir sobre seguro antes que arriesgar inversión en algo que no se sabe con certeza su éxito. El Carnaval de Cádiz ha sido históricamente identidad de marca de la cadena autonómica y también lo es de la cadena municipal, puesto que disfruta de una trayectoria exitosa. Esto que hemos mostrado hasta el momento ha sido pre pandemia. Estudios recientes (Montaña et.al, 2020; y Fieiras et. al., 2020) muestran que la televisión ha aumentado su audiencia durante el confinamiento. «Este encierro es una situación excepcional que ha causado nuevos modelos de vida, nuevos hábitos de consumo, y en particular, nuevos consumos de los medios de comunicación, así como del entretenimiento, del ocio y de la cultura» (Montaña et.al, 2020, p. 156). Es ese nuevo modelo de vida, sin contacto social y aislamiento obligatorio, el que choca con la tradición que aquí tratamos, que supone masas de gente en contacto directo.

Por otro lado, además de las emisiones en directo, las televisiones también cuentan con un repositorio cada vez más adaptado a los consumidores en internet. «Desde la existencia de los portales de las televisiones en internet, el telespectador puede acceder a sus contenidos cuando quiere y donde quiere, con una visualización no secuencial (avanzar, retroceder, parar...) y de forma más activa (comentar, compartir...).» (Anton y Guallar, 2014, p. 2). Y así ha seguido procediéndose durante el confinamiento.

Los programas no temporales, los que se emiten durante todo el año, adaptaron el formato siguiendo con sus mismos contenidos:

En general, la televisión recurre a las reposiciones de programas de humor y entretenimiento fuera de horas de prime time, se combina online y presencial para formatos de participación coral, se elimina el público y se derivan a las redes eventos que tenían hueco en las parrillas pero que el COVID-19 obliga a cancelar, como el caso del Festival de Eurovisión que celebra sus semifinales de modo simbólico con programación especial en YouTube y se incorpora a la programación de La 1 con formato enlatado no competitivo. (Fieiras et.al, 2020, p. 579).

Aunque de menor envergadura, podríamos hacer un símil con el COAC y Eurovisión. Son competiciones musicales muy esperadas cada año en la que los preparativos, el directo y el postconcurso son atentamente seguidos por televisión y redes sociales. 
Al igual que siguieron los programas diarios en las parrillas de televisión, por ejemplo: «Pasapalabra», «Sálvame», «Andalucía Directo», etc. también se crearon otros para el momento de pandemia:

Los cambios en la televisión no solo se dan en las rutinas de producción de contenidos, sino que se identifican variaciones en la programación como refuerzo de espacios de entretenimiento y nuevos programas de proyección social o educativa, especialmente en las cadenas autonómicas. Se reponen programas de humor y ocio, se combina online y presencial para formatos de participación coral, se elimina el público y se llevan a las redes espacios que antes tenían hueco en las parrillas. (Fieiras et.al, 2020, p. 582).

Pese a que vivimos en una sociedad altamente digitalizada y en la que los smarts phones lo copan todo, «los datos permiten afirmar el predominio de los medios tradicionales en situaciones altamente críticas, como el Covid-19.» (Casero-Ripollés, 2020 , p. 10). Aquí vamos a comprobar que las televisiones hicieron un esfuerzo para producir programas cuyo contenido casi en su totalidad está disponible de manera on line, pero el espectador gusta de ver el evento sin tener que buscar los contenidos de manera autónoma. Prefiere el conjunto que ofrecen los programas de televisión que aquí vamos a tratar: «El Concurso del Milenio» y «El Palco del Falla».

Tal y como ha pasado en otros momentos de catástrofe o crisis la información es relevante y prioritaria, pero la población también necesita compaginarla con el humor y entretenimiento, para poder evadirse de la crudeza de las noticias relacionadas con la COVID-19. (Montaña et.al, 2020, p. 164).

Esta idea ha sido repetida durante toda la emisión de «El Concurso del Milenio» y también reforzada por los presentadores de «El Palco del Falla».

[Llevar a cabo el Concurso del Milenio] está resultando un ejercicio maravilloso porque el objetivo de distraer y entretener a la gente, quitarle de la cabeza todo lo que estamos pasando con la pandemia del covid-19, creo que está siendo muy importante y es una terapia colectiva que nos está ayudando a todos a superar este momento de nuestras vidas (Declaraciones de Casal, 2021, programa de radio «La Azotea»).

«La radio, tal y como afirma Rodero (2020), y la televisión son los medios de mayor confianza depositada por la población, y, las redes sociales el de menor, a pesar del uso ascendiente y continuado en los últimos años.» (Montaña et.al, 2020, p. 163). La televisión, lejos de desaparecer tal y como la conocemos, se unió a internet en lugar de verlo como un rival y lo utilizó para su beneficio (Gordillo, 2009). Actualmente, los programas emblemas de las cadenas de televisión añaden sobreimpresionado un hashtag para ver cómo se comporta su audiencia digital.

Uno de los últimos eslabones de la cadena de producción del mensaje televisivo, los sistemas de medición de audiencias, también se están viendo afectados y están comenzando a incorporar nuevos métodos y herramientas, en definitiva, nuevas métricas, para poder tener el conocimiento más 
Fernández Jiménez, E. Cambios en la programación televisiva en Andalucía debido a la pandemia por la COVID-19. El caso del Carnaval de Cádiz

detallado posible de lo que ocurre en las redes sociales. (Día-Campo y Fernández-Gómez, 2020, 508 y 509).

De hecho, Casal y Peralta (2021), coinciden en hablar de la buena repercusión y acogida de los programas por parte de su audiencia en términos de repercusión digital. Ambos programas fueron trending topic durante su emisión diaria en sus respectivos horarios.

\section{PROGRAMACIÓN DE LAS TELEVISIONES ENCARgADAS DE RETRANSMITIR EL COAC}

Hay cuatro valores que debe poseer un programa de televisión:

«El valor intrínseco es el valor que un programa posee en sí mismo en relación a las posibilidades de triunfo en un esquema (parrilla) ya conocido por el telespectador. El valor posicional es aquel que tiene un programa en cuanto al lugar que ocupa en el esquema de la programación. El valor estratégico o de contraste es el que tiene un programa en función de ser contrastado con los programas que se emiten en la misma franja horaria por parte de la competencia. Y el valor económico es el que tiene un programa en virtud de su rentabilidad económica al ubicarse en un día, franja y lugar concretos frente a una competencia real.» (Sotelo et. al. 2020. p. 1627).

Aquí, la peculiaridad radica en que dos cadenas, Onda Cádiz y Canal Sur, emiten el mismo contenido matriz. La diferencia está en el tipo y forma de entrevistas, los pasos a publicidad y los presentadores. Además se trata de entes públicos, financiados por el gobierno regional y municipal, luego la ideología del partido que gobierne podría afectar a las maneras de emisión, ya que para muchos espectadores esto es determinante. Hasta la realización televisiva es la misma. Tras una copla, el espectador encuentra la diferencia en los comentarios que profieren los presentadores y comentaristas que ayudan a comprender la letra (Fernández Jiménez, 2020b) ${ }^{2}$. En este trabajo aplicamos el término «retransmisión» y no emisión ya que «El término retransmisión se aplica a las transmisiones desde la unidad móvil» (Zúñiga, 2006, p. 130). El concurso acontece fuera de las instalaciones de las televisiones. Como hemos expuesto al comienzo del trabajo, transcurre en el Gran Teatro Falla situado en el casco antiguo de la ciudad de Cádiz. Consecuentemente, los equipos de televisión han de desplazarse hasta allí para cubrir el concurso.

\subsection{Año 2020}

Debemos tener en consideración que la retransmisión del COAC se trata de la retransmisión de una competición, pero a esta competición se suma otra: la de las cadenas encargadas se difundirlo. Esta competición entre medios se hizo más explícita a finales de 2019 y principios de 2020, cuando Canal Sur y Onda Cádiz

\footnotetext{
${ }^{2}$ En algo sí difieren y es algo controvertido: la cantidad que paga cada televisión por los derechos de imagen.
} 
apuestan por retransmitir la Final. El Ayuntamiento se decantó por el ente municipal tras treinta años de emisión en exclusiva de la final por parte de Canal Sur. Tanto en prensa como en redes sociales se achacó este cambio a motivos técnicos, pero también a motivos políticos en los que este trabajo no va a entrar ${ }^{3}$. Finalmente, hubo un reparto y venta de los derechos y las fases de semifinales y final que retransmitieron a la vez, cada televisión con sus presentadores y producción. La señal y realización correspondía a Onda Cádiz y se la pasaba a Canal Sur.

El carnaval de 2020, fue el último pre pandémico, como hemos expuesto. Puede verse en la programación de Onda Cádiz cómo el Carnaval, del 17 al 23 de febrero de 2020, copa casi en su totalidad la parrilla televisiva (Véase Anexo 1).

Por su parte, Canal Sur, pese a haber perdido la exclusividad de la retransmisión de la fase final, retransmitió el concurso completo a través de la radio y las fases de semifinal y final por televisión. Al atender a las otras siete provincias, solo añadió el programa «Andalucía de Fiesta en Carnaval» como programa de temática carnavalesca del 17 al 23 de febrero de 2020. La semana previa, del 10 al 16 de febrero, emitió diversos documentales llamados «Creo en ti». En el mismo horario de estos documentales Onda Cádiz retransmitía la fase de cuartos de final. Por primera vez, la televisión municipal retransmitió en directo el concurso en todas sus fases: preliminares, cuartos de final, semifinales y final.

\subsection{Año 2021}

Como decimos, El Carnaval de Cádiz tuvo la suerte de poder celebrarse en su edición de 2020. No ocurre así en 2021. En este año, las televisiones encargadas tanto de retransmitir el concurso como de hacer reportajes temáticos y actuales de la fiesta se quedan sin contenido nuevo.

La crisis de la Covid-19 ha alterado las rutinas productivas de los periodistas, con el trabajo a distancia y la virtualización como actores principales del cambio hacia el periodismo remoto. Los profesionales de la información han tenido que dominar herramientas de producción a distancia, se han adaptado a horarios inéditos y han asumido nuevas responsabilidades que hasta la llegada de la pandemia no formaban parte de su día a día. El coronavirus ha actuado como agente del cambio, ya que ha forzado a los medios de comunicación a adoptar unas medidas que meses atrás se vislumbraban lejanas e incluso inviables. (Túñez et. al., 2020, p. 12).

\footnotetext{
${ }^{3}$ Durante semanas aparecían noticias sobre el cambio de exclusividad de los derechos de la final "Onda Cádiz arrebata a Canal Sur la retransmisión del Carnaval de Cádiz" https://www.lavozdigital.es/cadiz/provincia/lvdi-junta-coac-prefiere-onda-cadiz-frente-canal-televisionpara-retransmitir-carnaval-201911281956 noticia.html, [Consultado el 29/11/2019] o "El Carnaval pierde el norte" https://www.diariodecadiz.es/opinion/articulos/Carnaval-pierdenorte 0 1414958535.html [Consultado el 02/12/2019].
} 
Fernández Jiménez, E. Cambios en la programación televisiva en Andalucía debido a la pandemia por la COVID-19. El caso del Carnaval de Cádiz

Tan lejanas e impensables como el hecho de hacer un programa sobre el Carnaval de Cádiz desde el Teatro Falla, pero sin público. Solo se ocupó el palco de Onda Cádiz y puntualmente el escenario, como vamos a exponer a continuación.

\subsubsection{Canal Sur "El Concurso del Milenio"}

Manolo Casal, tras recibir el encargo por parte del director de Canal Sur Radio de crear una programación de carnaval que copara el hueco que han estado cubriendo durante treinta y dos años, vio oportuno:

Diseñar una programación que durase exactamente lo mismo que un Concurso [Desde el 18 de enero hasta el 12 de febrero de 2021]. Y luego me parecía también importante que fuera algo que tuviera cierto carácter competitivo por aquello de que en Cádiz eso gusta mucho (Cuestionario a Casal, 2021).

«La falta de espectáculos deportivos durante la etapa de confinamiento motivó el crecimiento de la única alternativa posible a la competición física: los torneos virtuales.» (Túñez et.al, 2020, p. 12). A esto responde este concurso. Consistía en seguir el esquema y normas del concurso oficial, pero haciendo que participasen mediante el archivo histórico de la cadena las agrupaciones que mejor quedaron clasificadas en sus respectivos años desde el 2000 hasta el 2019. 60 comparsas, 60 chirigotas, 20 coros y 10 cuartetos competían entre sus respectivas modalidades. El contenido se hizo con los audios originales del concurso grabados por Canal Sur Radio y ensamblados con sonidos ambiente de archivo del propio teatro durante los concursos. A estos audios se le añade en directo los comentarios locutados en 2021 de los presentadores. Según Casal (2021) lo más complicado de la producción que este programa fue poder recopilar todas las coplas y que estuvieran en buen estado para poder ser escuchadas con nitidez. El desarrollo en directo, una vez se tenía toda la producción preparada, afirma, fue lo más fácil.

Se dieron casos en los que el mismo autor competía contra sí mismo con varias agrupaciones a la vez, ya que en general cada autor de su modalidad saca una agrupación por año, incluso hay autores que compiten con varias agrupaciones de modalidades dispares. Esto añadía cierta peculiaridad a este concurso. Ahora sí, se trata de un concurso radiofónico y no radiado. En esta ocasión el medio decidió el número de agrupaciones que competían (regido por su clasificación real en el concurso de cada año), el número de agrupaciones por sesión y la duración de las mismas. Para hacerlo más fiel al original y tener presente la competición, se eligió un jurado externo al medio de comunicación que fue el que determinó qué agrupaciones pasaban de fase. Además, por primera vez se puso a disposición de los espectadores el tele voto. La audiencia pudo elegir a su agrupación ganadora, aparte del premio del jurado oficial.

Para este concurso fue muy importante el pacto de ficción hecho entre los presentadores y aficionados al que se les unieron las agrupaciones «participantes», «haciéndonos revivir ensayos, sesiones de maquillaje y pasacalles a través de vídeos 
de la época en las redes sociales» (Cuestionario a Casal, 2021) ${ }^{4}$. «Los medios de comunicación tradicionales como la prensa, la radio y la televisión han pretendido cumplir su papel ético dando cuenta de las desinformaciones y fake news aparecidas en redes sociales posicionándolas en su agenda setting.» (Morejón Llamas, 2021: 120). Pese a «jugar» a que estaban en el teatro durante la emisión en directo de una sesión de «El Concurso del Milenio», interrumpieron el programa para dar información en tiempo real sobre los terremotos ocurridos en Granada. La actualidad apremia en situaciones de urgencia en el medio público.

Como decimos, este programa nace en el medio radiofónico, pero fue tal su repercusión en redes sociales que desde el primer programa los aficionados demandaron su presencia en televisión para todas las fases del concurso. Finalmente la cadena autonómica apostó por pasar a la televisión la fase final.

Canal Sur Televisión emitió la final del Concurso del Milenio como hubiera transmitido la final del COAC en condiciones normales. La final del concurso de la radio estaba prevista para el mismo día de la final del Falla, si ésta se hubiera celebrado. Así que se dieron todas las circunstancias favorables y la televisión apostó por la final del Milenio, incluyendo en su parrilla lo que es habitual desde 1990 [...] Mucha gente nos lo decía en las redes sociales. Lo daban por hecho. Y así ocurrió. [...] montamos un set con pantallas gigantes en el Parador Hotel Atlántico, ofreciendo una imagen espectacular que no se puede dar desde el palco del teatro (Cuestionario a Casal, 2021)

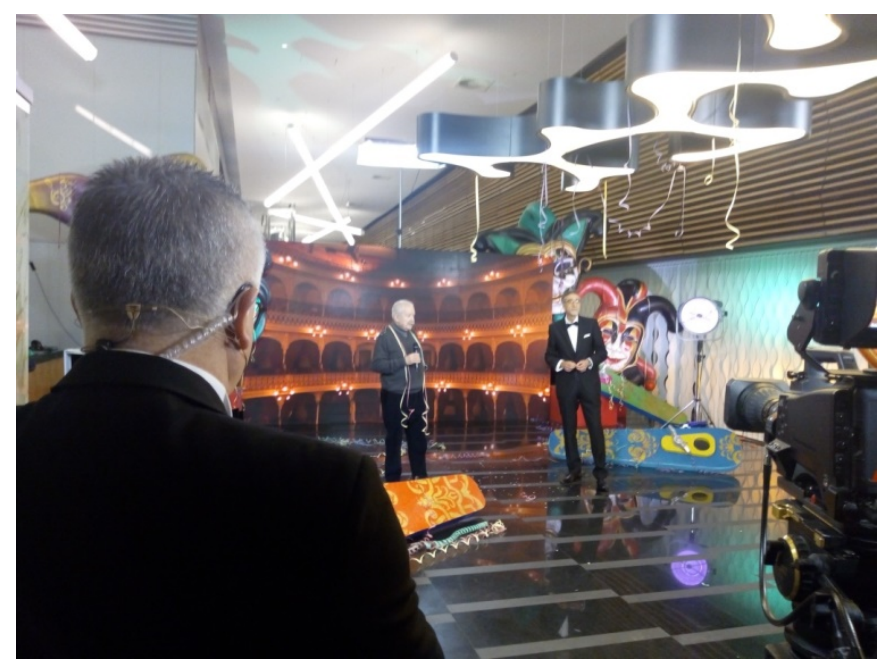

Imagen 1. Set de Canal Sur Televisión montado en el Hotel Parador Atlántico para la Final del Milenio.

Fuente: Elaboración propia

\footnotetext{
${ }^{4}$ Pueden escucharse las sesiones del concurso en el siguiente enlace https://www.canalsur.es/radio/programas/el-concurso-delmilenio/detalle/16204229.html?video $=1680272$
} 
En la imagen 1 aparecen de izquierda a derecha: De espaldas Manolo Casal director y presentador del programa; Julio Pardo, invitado y participante en la Final; y Juan Manzorro, presentador del programa.

«Un aspecto central de los eventos deportivos en televisión es el suspense de no saber el resultado o desenlace de la competición» (Marín, 2002, 44-45). Lo llamativo de este concurso es que las agrupaciones participantes ya habían sido clasificadas en sus respectivos años, pero ahora, al tener un jurado diferente y único para puntuar las 150 agrupaciones de los últimos 20 años otorgaban un halo de misterio o enigma a cuáles serían las vencedoras en 2021.

\subsubsection{Onda Cádiz "El Palco del Falla"}

Onda Cádiz venía de retransmitir el concurso en su totalidad el año anterior y como hemos visto en el Anexo1, de cubrir casi la totalidad de la parrilla televisiva con temática carnavalesca. En 2021 también se vieron en la necesidad de ofrecer algo a su audiencia que pudiera llenar el hueco que dejaba la suspensión del COAC y del carnaval callejero. Su programa fue «El Palco del Falla». Según nos cuenta Peralta (2021) en principio, la programación iba a consistir en retransmitir unas galas que había organizado el Ayuntamiento con las agrupaciones semifinalistas y finalistas del año 2020, pero por la tercera ola aparecida tras las navidades generada por la Covid, decidieron suspenderse. Tras esto:

Fue cuando nos pusimos a definir concretamente lo que iba a ser «El Palco del Falla» [...] pensamos en hacer algo más transversal, porque la calidad de imagen, evidentemente de los ochenta, hacía inviable que hubiera, por ejemplo, tres horas de un programa dedicado a la primera mitad de los ochenta [...] ideamos 14 temas que iban a ser 14 programas (Cuestionario a Peralta, 2021).

Además, como eran conscientes de la programación de la televisión regional intentaban «justificar constantemente que esto no era un concurso, si no que quería ser una muestra que fuera representativa de cada uno de los temas que habíamos ido proponiendo para cada programa» (Cuestionario a Peralta, 2021). Las dificultades encontradas para llevar a cabo este programa, según afirma la periodista, era el miedo por parte de algunos invitados a asistir a las entrevistas y no solo el miedo al contagio, tuvieron que gestionar la programación y cambiar en varias ocasiones la temática y a los invitados ya que al haber sido alguno de ellos contacto estrecho con alguna persona contagiada, o solo sospechosa, debían permanecer aislados y consecuentemente, no acudir al programa. Peralta coincide con Casal que en términos periodísticos y de comunicación lo más fácil fue el trabajo en directo ya que contaban con el mismo equipo técnico de trabajadores y el arduo trabajo previo de documentación estaba resuelto. Además de las dificultades de las agendas y disponibilidad de los invitados, Peralta manifiesta que la inclusión de sonidos ambientes en un teatro vacío también resultó extraño y complicado. El cambio más destacado en la programación respecto al año anterior fue el adelanto horario: 
A la hora de determinar los horarios teníamos muy claro que queríamos ser la excusa para que la gente permaneciera en casa en la medida de lo posible y contribuir así, modestamente, como servicio público y evitar mayor propagación del virus. Como a las seis de la tarde cerraban todos los establecimientos que no eran esenciales durante esa época, pensamos que era la hora idónea, hacerlo de seis a nueve, tres horas de duración que nos parecía un esquema lógico y viable [...] únicamente fue en horario nocturno la final por ser también fieles a la tradición (Cuestionario a Peralta, 2021).

Si observamos el Anexo 2 apreciamos estos cambios. Y comparándolo con la parrilla de 2020, Anexo 1, vemos la drástica reducción de horas destinadas a programación carnavalesca, de 107 horas en el año anterior a la pandemia, a 41.5 en 2021.

Por la pandemia, «La televisión recupera así la audiencia de los más jóvenes que parecía haber perdido a favor de los medios digitales, consolidando un panorama mediático cada vez más complejo y competitivo.» (Montaña et.al, 2020, p. 155) Durante «El Concurso del Milenio», recibieron mensajes de jóvenes que había consumido más radio de la habitual debido al seguimiento del concurso y consecuentemente migraron a verlo en televisión. Por su parte, Peralta (2021) afirma que «muchas personas han descubierto el carnaval de los ochenta y principios de los noventa a través de ente programa».

\section{CONCLUSIONES}

Este trabajo constata la siguiente afirmación:

En la parte operativa, la pandemia ha obligado a encarar un modo diferente de producir todo tipo de contenidos, tanto informativos como de entretenimiento, ajustes en el modo de cubrir y elaborar las noticias, cambios en los modelos de producción con nuevas vías que busquen calidad a menor coste, un reajuste en los estándares técnicos, y también nuevas maneras de relacionarse con la audiencia. Se ha producido una hibridación de la producción online y offline, con derivaciones en ambos sentidos que permite hablar de, por ejemplo, sinergias de colaboración entre la televisión tradicional y plataformas de eventos online, como Twitch. (Túñez et.al, 2020, p. 15).

Observamos, además, que los costes de estos dos programas no van más allá de las labores de producción y realización de los mismos con los sueldos de los trabajadores del medio. Las entrevistas y colaboraciones (y actuaciones de «El Palco del Falla») de ambos programas se han realizado de manera gratuita y el contenido principal se trataba de material grabado.

Aquí se ha visto que la creatividad es una parte fundamental en la televisión, no solo en los contenidos que se emiten, en este caso las coplas del carnaval que son creativas, sino que además, existe una creatividad en el formato. Los directivos y periodistas han sido capaces de recuperar algo que se daba por perdido en el 2021. 
Por parte de Canal Sur sostienen que «la radio ha impuesto su magia, se ha reivindicado como medio de comunicación del concurso y ha recuperado su posicionamiento» (Cuestionario a Casal, 2021) y además, ha afianzado las sinergias de las diferentes vías de comunicación:

Vivimos sumergidos en un panorama mediático competitivo, saturado de contenidos -existe una hibridación entre los medios tradicionales y los digitales que produce una complementariedad de los mismos, en el proceso de recopilación de información- y donde es difícil decidir qué información escoger. (Montaña et.al, 2020, p. 157).

Estas cadenas de televisión han ofrecido la información a escoger. Debemos tener presente dos cuestiones: Los contenidos que surtían a estos programas competían contra contenido actual o nuevo y en directo de otras cadenas. Asimismo, era material que en su amplia mayoría estaba con anterioridad disponible en internet, pero la manera de presentarlo, Onda Cádiz en formato ilustrativo con actuaciones en directo y Canal Sur en formato de concurso, añadían atractivo al contenido aparentemente visto y conocido por la audiencia.

En la emisión de estos programas, por el nivel de especialización que requieren los presentadores, al igual que en las retransmisiones deportivas, se añadía el riesgo de que durante las dos semanas que duró «El Palco del Falla» y las cuatro semanas que duró «El Concurso del Milenio» alguno de los presentadores o su entorno debieran permanecer en aislamiento preventivo y no poder realizar su trabajo de manera presencial. Lo cual no ocurrió.

Concluimos también con la idea de la importancia de la conservación y adecuada documentación del patrimonio audiovisual y en este caso también cultural de los medios de comunicación. Observamos que esta cita anual, el Carnaval de Cádiz, ha podido estar presente en la programación televisiva sin que se produjera el evento de manera normal gracias a los archivos audiovisuales. Es cierto que el carnaval en la calle, los que muchos postulan como verdadero carnaval o el carnaval puro, no se ha podido llevar a cabo ya que necesita obligatoriamente congregación de personas en un espacio muy pequeño pese a ser al aire libre en las calles. Han sido las imágenes del muy denostado concurso lo que ha permitido a los aficionados poder evadirse y rescatar coplas del pasado.

Este trabajo ofrece una visión general de varios aspectos intervinientes en la emisión de los programas: la parrilla, los contenidos de los programas y la opinión de los trabajadores y creativos de los programas. Centrarnos solo en uno de estos aspectos carecería de interés, es la visión general la que ha permitido comprender los cambios realizados. Además, en próximos carnavales si la pandemia sigue impidiendo su realización, volverán a ser los creativos de televisión los que deban procurar material que surta la demanda de la audiencia, a poder ser sin repetir las fórmulas aquí estudiadas. 
Fernández Jiménez, E. Cambios en la programación televisiva en Andalucía debido a la pandemia por la COVID-19. El caso del Carnaval de Cádiz

Un estudio secundario de esta situación pudiera ser el análisis de las coplas de carnaval de hace veinte años en la actualidad. «El Concurso del Milenio» y «El Palco del Falla» han servido de manera soterrada para apreciar cómo ha cambiado la sociedad en los últimos veinte años. En 2021 se han escuchado coplas sobre economía, política, sociedad, machismo, religión, educación, etc. las cuales han podido percibirse de manera diferente a como se escucharon por primera vez.

Debiera hacerse un estudio sobre las devastadoras repercusiones económicas en la ciudad y trabajadores que ven incrementados sus ingresos con la celebración tanto del Concurso como de la fiesta en sí.

Por último, con este trabajo de manera secundaria hemos buscado ampliar la, cada vez más numerosa, bibliografía científica sobre Carnaval de Cádiz la cual está en continua expansión y visibilidad tras la creación de la Cátedra de Carnaval en la Universidad de Cádiz en 2018.

Sabemos que puede quedar desfasado este estudio debido a la temática y velocidad de cambio del medio televisivo. Es un riesgo que asumimos cuando escribimos sobre fenómenos comunicacionales.

\section{REFERENCIAS}

Aragón, J. C. (2010). El Carnaval sin apellidos. Un arte mayor para una chusma selecta. Artes Gráficas Nueva.

Anton, L.; Guallar, J. (2014). Análisis de los archivos audiovisuales en internet de las televisiones autonómicas españolas. Revista Española de Documentación Científica, 371).http://dx.org/10.3989/redc.2014.1.1044

Bajtin, M. (1990). La cultura popular en la Edad Media y en el Renacimiento. El contexto de François Rebelais. Alianza.

Casero-Ripollés, A. (2020). Impact of Covid-19 on the media system. Communicative and democratic consequences of news consumption during the outbreak. El profesional de la información, 29(2). https://org/10.3145/epi.2020.mar.23

Checa, F. (1992). El humor andaluz, ¿Identidad de un pueblo?. En El Folklore Andaluz. Revista de cultura tradicional, 8, Fundación Machado, 55-84.

Devesa, M. (2021). Programa de radio La Azotea. Radio la Isla. 12 de febrero de 2021. https://www.youtube.com/watch?app=desktop\&v=ioRCK1 a-Ig+

Díaz-Campo, J. y Fernández-Gómez, E. (2020). Las televisiones autonómicas públicas en Facebook. Análisis de la situación de TV3, Aragón TV, TVG y Canal Sur en 2015. Estudios sobre el Mensaje Periodístico 26(2), 507-518. https://org/10.5209/esmp.67587 
Fernández Jiménez, E. Cambios en la programación televisiva en Andalucía debido a la pandemia por la COVID-19. El caso del Carnaval de Cádiz

Fernández Jiménez, E. (2018). La Final del Falla: Un estudio sobre la realización televisiva del COAC. Servicio de Publicaciones de la Universidad de Cádiz.

Fernández Jiménez, E. (2020a). Prensa, radio, televisión e internet: el cuarteto que acompaña al carnaval de Cádiz. Comunicación en Congreso GKA Arts 2020. https://www.youtube.com/watch?v=|rkZpTb1gD8

Fernández Jiménez, E. (2020b). Características periodísticas en la retransmisión de cultura popular: Concurso Oficial de Agrupaciones Carnavalescas de Cádiz. En (Nuria Sánchez-Gey Valenzuela \& Susana Alés Álvarez) Los Medios de Comunicación como agentes de educación social. Ediciones Egregius.

Fieiras Ceide, C., Túñez López, M., Vaz Álvarez, M., (2020). Impacto del COVID-19 en la televisión en España: contenidos, audiencias, soportes y estrategias de producción. Revista Ibérica de Sistemas e Tecnologias de Informação. Iberian Journal of Information Systems and Technologies. 35, 572-585.

Giménez, G. (2012).El problema de la generalización en los estudios de caso. Cultura y representaciones sociales. (13), 40-62.

Gordillo, I. (2009). La Hipertelevisión: géneros y formatos. Ciespal.

Huizinga, J. (1987). Homo ludens. Alianza.

Marín Montín, J. (2003). Las retransmisiones deportivas en televisión. En Comunicación: Revista internacional de Comunicación Audiovisual, Publicidad y Estudios Culturales. N02, 41-50.

Millerson, G. (1990). Técnicas de Realización y Producción en Televisión. RTVE.

Montaña Blasco, M.; Ollé Castellà, C. y Lavilla Raso, M. (2020). Impacto de la pandemia de Covid-19 en el consumo de medios en España. Revista Latina de Comunicación Social, 78, 155-167. https://www.org/10.4185/RLCS$\underline{2020-1472}$

Morejón Llamas, N. (2021). Infodemia y dependencia informativa: la función ética de la televisión pública andaluza durante la crisis del Covid-19. Comunicación y Hombre. no 17, 119-138. https://org/10.32466/eufv-cyh.2021.17.658.119-138

Ramos, A. (2002). El Carnaval Secuestrado o Historia del Carnaval. El caso de Cádiz. Quorum Editores.

Reig, R., Mancinas-Chávez, R., Nogales-Bocio, A. I., (2014). Un acercamiento en 2014 a la conformación de la estructura audiovisual en España y el caso de Canal Sur TV. Revista Latina de Comunicación Social, 69, 571-617. 10.4185/RLCS-2014$\underline{1026}$ 
Fernández Jiménez, E. Cambios en la programación televisiva en Andalucía debido a la pandemia por la COVID-19. El caso del Carnaval de Cádiz

Osuna, J. (2009). El periodismo en tiempos de Carnaval. 1763-2005 (más linotípico no lo hay). Quorum Editores.

Pellisser Rossell, N, y Pineda, A. (2014). Información política televisiva y espectacularización: un análisis comparativo de programas informativos y de infoentretenimiento. Estudios sobre el Mensaje Periodístico. 20(2), 821-839. http://dx.org/10.5209/rev ESMP.2014.v20.n2.47036

Ramonell, M. (2006). La televisión autonómica en España. Chasqui. Revista Latinoamericana de Comunicación, https://org/10.16921/chasqui.v0i93.218

(93),

34-39.

Sotelo-González, J., Sierra-Sánchez, J., y Cabezuelo-Lorenzo, F. (2020). Evolución de las programaciones de Telecinco-Cuatro y Antena 3-La Sexta tras la concentración del mercado de la televisión en España. Estudios sobre el Mensaje Periodístico 26 (4), 1623-1643. http://dx.org/10.5209/esmp.67246

Túñez-López, M., Vaz-Álvarez, M., Fieiras-Ceide, C., (2020). Covid-19 and public service media: Impact of the pandemic on public television in Europe. Profesional de la información, 29(5). https://org/10.3145/epi.2020.sep.18

Zúñiga, J. (2006). Realización en televisión. Escuela de cine y vídeo.

\section{AUTOR:}

\section{Estrella Fernández Jiménez}

Licenciada en Comunicación audiovisual y Doctora por la Universidad de Sevilla. Sus principales líneas de investigación son los medios de comunicación, la realización televisiva, el Carnaval de Cádiz, la comunicación no verbal, la cultura y el humor. Ha trabajado en empresas relacionadas con la comunicación y como profesora de español para extranjeros y en la Universidad de Cádiz en el área de Comunicación audiovisual y Publicidad. Ha dirigido y presentado el programa de radio "Mira que te diga" en INDESS Media (UCA) abordando la comunicación no verbal en la sociedad y en el mundo artístico. En 2018 realizó la charla TEDx "Raphael ¿Me lo cantas o me lo cuentas?"

estrellaffj@us.es

Orcid ID: https://orcid.org/0000-0001-9589-5190

Google Scholar: https://scholar.google.es/citations?user=yb3by28AAAAJ\&hl=es

ResearchGate: I-4153-2018

Academia.edu:

https://independent.academia.edu/EstrellaFern\%C3\%A1ndezJim\%C3\%A9nez 
Fernández Jiménez, E. Cambios en la programación televisiva en Andalucía debido a la pandemia por la COVID-19. El caso del Carnaval de Cádiz

\section{ANEXOS}

\section{PARRILLA DE PROGRAMACIÓN DE ONDA CÁDIZ TELEVISIÓN DEL LUNES 17 DE FEBRERO DE 2020 AL DOMINGO 23 DE FEBRERO DE 2020.}

Hemos señalado en color amarillo la retransmisión del COAC en directo. En verde mostramos la programación relacionada con algún aspecto del carnaval de ese mismo año. (Fuente: Dirección de realización de Onda Cádiz TV).

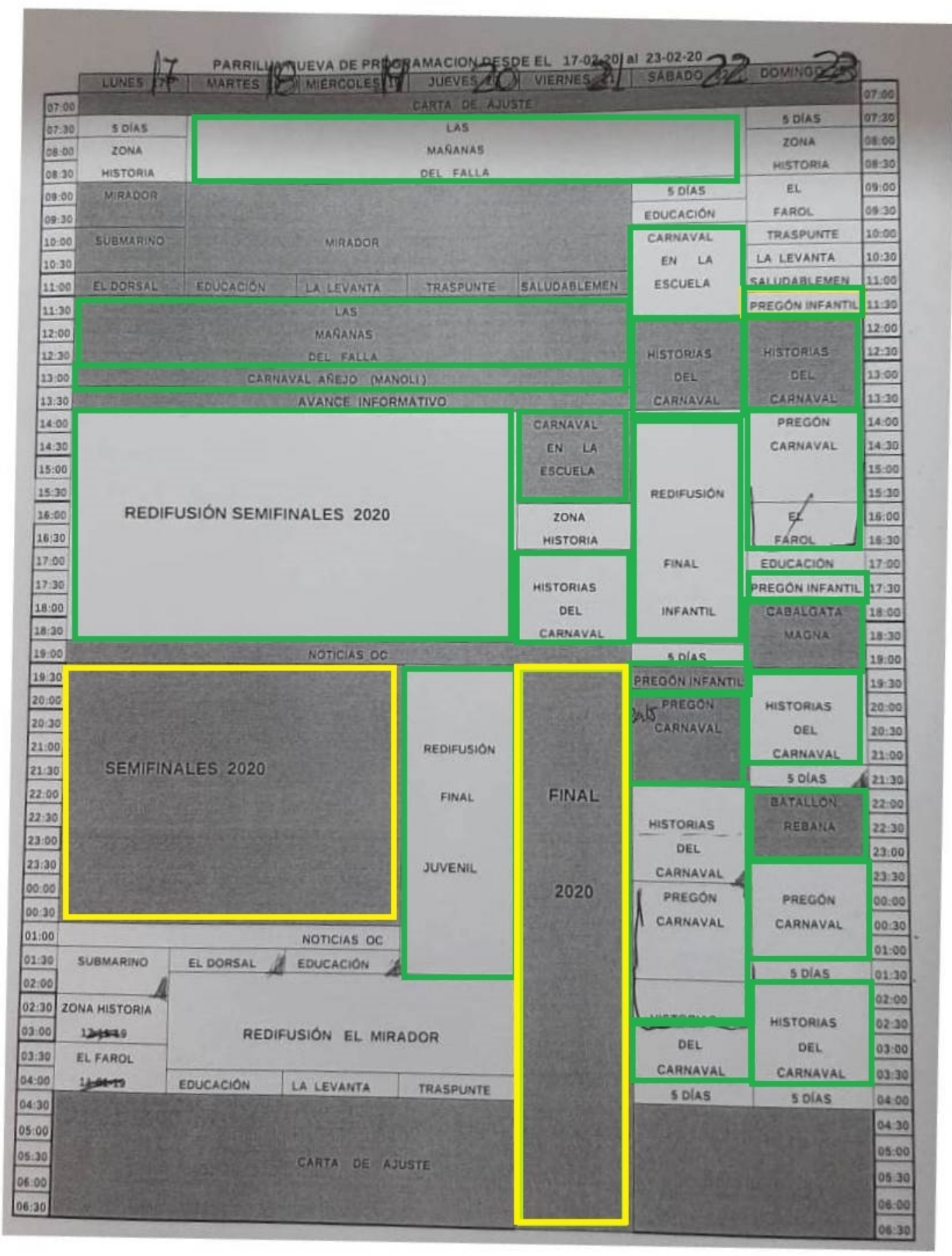


Fernández Jiménez, E. Cambios en la programación televisiva en Andalucía debido a la pandemia por la COVID-19. El caso del Carnaval de Cádiz

\section{PARRILLA DE PROGRAMACIÓN DE ONDA CÁDIZ TELEVISIÓN DEL LUNES 8 DE FEBRERO DE 2021 AL DOMINGO 14 DE FEBRERO DE 2021.}

Hemos señalado en color amarillo la retransmisión del «Palco del Falla» en directo. En naranja las redifusiones de este programa y en verde mostramos la programación relacionada con algún aspecto del carnaval. (Fuente: Dirección de realización de Onda Cádiz TV).



